\title{
Meninjau Ulang Penggunaan Besaran Konsentrasi Normalitas pada Kimia Larutan
}

\author{
Reviewing the Usage of Magnitude of Normality Concentration
}

\author{
Soebiyanto $^{1 *}$, Petrus Darmawan ${ }^{2}$ \\ ${ }^{1}$ Fakultas Ilmu Kesehatan Universitas Setia Budi \\ ${ }^{2}$ Fakultas Teknik Universitas Setia Budi Surakarta \\ *Corresponding author: soebixto@gmail.com
}

\section{ABSTRAK}

Pada volumetri, beberapa ahli kimia lebih lancar menyelesaikan hitungan kimia jika perbandingan zat yang bereaksi, adalah sama yaitu $1: 1$ secara stokiometri. Selama ini kita ketahui hampir semua buku petunjuk praktikum menggunakan suatu besaran konsentrasi yang disebut normalitas ( $N)$.

Sebagaimana kita ketahui, bahwa molaritas suatu larutan secara langsung dapat dibuat dari penimbangan kristal suatu zat atau dapat dibuat dari pengenceran larutan pekatnya. Namun normalitas suatu larutan disamping tergantung pada molaritas larutan, sangat tergantung pula pada reaksi yang akan terjadi pada zat itu.

Dengan demikian normalitas tidak dapat ditentukan ataupun dibuat jika tidak diketahui reaksi yang akan terjadi pada saat itu.

Pengunaan normalitas dalam hitungan kimia larutan dirasakan sangat menyulitkan dan membingungkan sehingga penggunaannya perlu ditinjau ulang. Hal ini dikarenakan beberapa hal diantaranya: penyelesaian hitungan kimia larutan dengan menggunakan konsep normalitas hanya dapat diselesaikan jika ekivalen zat yang bereaksi selalu sama dan normalitas larutan hanya dapat ditentukan bila ek atau mek zat itu dalam volum larutan tertentu dapat ditentukan atau persamaan reaksi yang akan terjadi pada zat itu telah diketahui dengan pasti.

Kata kunci: normalitas, kimia larutan

\section{ABSTRACT}

In volumetry, some chemists have completed the comparison of chemical count. Smoothly when its comparison of the reacting substance was on same level, namely1:1 stoichiometrically. As far as we know, mostly of practices manuals have used a magnitude of concentration which is called normality ( $N)$.

As we have known, that molarity of solution can be produced directly from crystal weighing of substance or can be made from dilution of the concentrated solution. However, the normality of a solution depends on its solution molarity, as well as Completely depending on the reaction supposing to occur in substance mentioned above. Therefore the normality can not be determined or processed without identiying the reaction occuring in it at the same time.

The usage of normality in counting the chemical solution has been regarded as very troublesome and confusing, therefore we should review on the usage. This is duing to several factors, which include: the counting of chemical solution by using a kind of normality concept that only can be completed whenever the reacting equivalent substance being on same level and normality of solution. Only can be determined if its eq or meq of the solution in certain solution volume can be determined or if the equation of reaction that will occur at that time have been identified with certainty.

Keywords: normality, chemical solution

\section{PENDAHULUAN}

Pada volumetri, jika kita akan mengukur jumlah atau kadar suatu analit dalam suatu sample, hal itu dapat dengan mengukur jumlah zat yang diperlukan untuk bereaksi dengan analit itu secara sempurna. Sebagai contoh jika kita akan menentukan jumlah suatu basa dalam larutan, maka penentuan itu dilakukan dengan mengukur jumlah asam ter- tentu yang diperlukan untuk bereaksi dengan basa tersebut. Dalam konteks ini, yang akan diukur adalah jumlah asamnya, tetapi yang ingin diketahui adalah jumlah basanya (Sudarmadji et. al., 1984)

Beberapa ahli kimia lebih lancar menyelesaikan hitungan kimia jika perbandingan zat yang bereaksi, adalah sama yaitu 1: 1 secara stokiometri. Selama ini kita ketahui hampir semua bu- 
ku petunjuk praktikum menggunakan suatu besaran konsentrasi yang disebut normalitas (N). Memang besaran konsentrasi normalitas sudah digunakan sejak lama, terutama pada volumetri. Namun pada saat ini, banyak ahli kimia mulai meninggalkan penggunaan normalitas itu. Implementasi dari hal ini, mungkin bisa kita cermati pada Kurikulum SMU dan MA tahun 1994 berikut Suplemennya, bahkan Kurikulum saat ini yang terbarupun tidak lagi mencantumkan dan membahas besaran konsentrasi normalitas larutan (Depdikbud, 1985).

\section{NORMALITAS}

Normalitas didefinisikan sebagai jumlah ekivalen zat terlarut dalam satu liter larutan atau miliekivalen zat terlarut dalam satu mililiter $(\mathrm{mL})$ larutan, yang mengandung zat terlarut itu.

Ekivalen suatu zat, merupakan suatu satuan jumlah dan berhubungan dengan berat zat tersebut, melalui berat ekivalennya atau istilah lainnya yaitu Grek (gramekivalen). Untuk seterusnya pada tulisan ini digunakan istilah Grek. Gramekivalen suatu zat tergantung pada reaksi zat tersebut (Krieger, 1997).

\section{Menentukan Gramekivalen}

Berat 1 Grek suatu larutan tergantung pada macam atau tipe reaksinya. Akan berlainan jika ditetapkan dengan cara yang berbeda.

I. Grek dalam Asidimetri dan Alkalimetri

a. Berat 1 grek asam = berat asam tersebut yang $\sim 1$ grion $\mathrm{H}^{+}$atau $1,008 \mathrm{~g} \mathrm{H}$

Contoh :

1). $\mathrm{HCl} \rightleftarrows \mathrm{H}^{+}+\mathrm{Cl}^{-}$

1 grol $\mathrm{HCl} \sim 1$ grion $\mathrm{H}^{+}$

1 grek $\mathrm{HCl}=1$ grol $\mathrm{HCl}$

2). $\mathrm{H}_{2} \mathrm{SO}_{4} \rightleftarrows 2 \mathrm{H}^{+}+\mathrm{SO}_{4}{ }^{=}$

1 grol $\mathrm{H}_{2} \mathrm{SO}_{4} \sim 2$ grion $\mathrm{H}^{+}$

1 grek $\mathrm{H}_{2} \mathrm{SO}_{4}=1 / 2$ grol $\mathrm{H}_{2} \mathrm{SO}_{4}$

3). $\mathrm{H}_{3} \mathrm{PO}_{4} \rightleftarrows 3 \mathrm{H}^{+}+\mathrm{PO}_{4}^{3-}$

1 grol $\mathrm{H}_{3} \mathrm{PO}_{4} \sim 3$ grion $\mathrm{H}^{+}$

1 grek $\mathrm{H}_{3} \mathrm{PO}_{4}=1 / 3$ grol $\mathrm{H}_{3} \mathrm{PO}_{4}$
Kesimpulan :

1. Asam monobasis: 1 grek $=1$ grol

2. Asam dibasis: 1 grek $=1 / 2$ grol

3. Asam tribasis: 1 grek $=1 / 3$ grol

b. Berat 1 grek basa $=$ berat basa tersebut yang $\sim 1$ grion $\mathrm{OH}^{+}$

Contoh :

1). $\mathrm{NaOH} \rightleftarrows \mathrm{Na}^{+}+\mathrm{OH}^{-}$

1 grol $\mathrm{NaOH} \sim 1$ grion $\mathrm{OH}^{-}$

1 grek $\mathrm{NaOH}=1$ grol $\mathrm{NaOH}$

2). $\mathrm{Ca}(\mathrm{OH})_{2} \rightleftarrows \mathrm{Ca}^{2+}+2 \mathrm{OH}^{-}$

1 grol $\mathrm{Ca}(\mathrm{OH})_{2} \sim 2$ grion $\mathrm{OH}^{-}$

1 grek $\mathrm{Ca}(\mathrm{OH})_{2}=1 / 2 \operatorname{grol~} \mathrm{Ca}(\mathrm{OH})_{2}$

Kesimpulan :

1. Basa berasam $1: 1$ grek $=1$ grol

2. Basa berasam $2: 1$ grek $=1 / 2$ grol

3. Basa berasam $3: 1$ grek $=1 / 3$ grol

Untuk garam yang larutannya bersifat alkalis dilihat dari reaksi garam tersebut dengan asam, misalnya :

$\mathrm{Na}_{2} \mathrm{CO}_{3}$ :

-Dengan indikator Phenolphtalein

$\mathrm{Na}_{2} \mathrm{CO}_{3}+\mathrm{HCl} \stackrel{\text { p.p }}{\longrightarrow} \mathrm{NaCl}+\mathrm{NaHCO}_{3}$

1 grol $\mathrm{Na}_{2} \mathrm{CO}_{3} \sim 1$ grol $\mathrm{HCl} \sim 1$ grion $\mathrm{H}^{+}$

1 grek $\mathrm{Na}_{2} \mathrm{CO}_{3}=1$ grol $\mathrm{Na}_{2} \mathrm{CO}_{3}$

-Dengan indikator Methyl orange

$\mathrm{Na}_{2} \mathrm{CO}_{3}+2 \mathrm{Hcl} \stackrel{\mathrm{m} . \mathrm{O}}{\longrightarrow} 2 \mathrm{NaCl}+\mathrm{H}_{2} \mathrm{O}+\mathrm{CO}_{2}$

1 grol $\mathrm{Na}_{2} \mathrm{CO}_{3} \sim 2$ grol $\mathrm{HCl} \sim 2$ grion $\mathrm{H}^{+}$

1 grek $\mathrm{Na}_{2} \mathrm{CO}_{3}=1 / 2$ grol $\mathrm{Na}_{2} \mathrm{CO}_{3}$

II. Grek dalam kompleksometri dan Presipitimetri

Berat 1 grek zat = berat zat tersebut yang mengandung atau dapat bereaksi dengan 1 grat kation yang bervalensi 1 atau $1 / 2$ grat kation yang bervalensi 1 , dst.

Contoh :

1). $\mathrm{AgNO}_{3} \longrightarrow \mathrm{Ag}^{+}+\mathrm{NO}_{3}^{-}$

1 grol $\mathrm{AgNO}_{3} \sim 1$ grat $\mathrm{Ag}$

1 grek $\mathrm{AgNO}_{3}=1$ grol $\mathrm{AgNO}_{3}$

2). $\mathrm{FeSO}_{4} \rightarrow \mathrm{Fe}^{2+}+\mathrm{SO}_{4}^{=}$

1 grol $\mathrm{FeSO}_{4} \sim 1$ grat $\mathrm{Fe} \sim 2 \times 1 / 2$ grat Fe

1 grek $\mathrm{FeSO}_{4}=1 / 2$ grol $\mathrm{FeSO}_{4}$ 
Dalam kompleksometri: grek didapat dengan menuliskan persamaan reaksinya :

Contoh :

1). $\mathrm{CN}^{-}+\mathrm{Ag}^{+} \longrightarrow[\mathrm{Ag}(\mathrm{CN})]^{-}$

1 grion $\mathrm{CN}^{-} \sim 1$ grion $\mathrm{Ag}^{+}$

1 grek $\mathrm{CN}^{-}=1$ grol $\mathrm{CN}^{-}$

2). Titrasi $\mathrm{Zn}^{2+}$ dengan $\mathrm{K}_{4} \mathrm{Fe}(\mathrm{CN})_{6}$

$3 \mathrm{Zn}^{2+}+2 \mathrm{~K}_{4} \mathrm{Fe}(\mathrm{CN})_{6} \longrightarrow 6 \mathrm{~K}^{+}+\mathrm{K}_{2} \mathrm{Zn}_{3}\left[\mathrm{Fe}(\mathrm{CN})_{6}\right]$

1 grol $\mathrm{K}_{4} \mathrm{Fe}(\mathrm{CN})_{6} \sim 3 / 2$ grion $\mathrm{Zn}^{2+}$

$\sim 6 / 2 \times 1 / 2$ grion $\mathrm{Zn}^{2+}$

$=3$ grek $\mathrm{K}_{4} \mathrm{Fe}(\mathrm{CN})_{6}$

1 grek $\mathrm{K}_{4} \mathrm{Fe}(\mathrm{CN})_{6}=1 / 3$ grol $\mathrm{K}_{4} \mathrm{Fe}(\mathrm{CN})_{6}$

III. Grek dalam Oksidimetri dan Reduktometri Dapat ditentukan dengan beberapa cara :

1. Dengan sistem oksigen

2. Dengan sistem elektron

3. Dengan perubahan bilangan oksidasi

1. Dengan sistem Oksidasi

1 grek oksidator/reduktor adalah banyaknya oksidator/reduktor yang dapat menerima/ melepaskan $1 / 2$ grat $\mathrm{O}$ atau $8 \mathrm{~g}$ oksigen.

Contoh Oksidator :

a. $2 \mathrm{KMnO}_{4}$ (asam) $\rightarrow \mathrm{K}_{2} \mathrm{O}+2 \mathrm{MnO}+5 \mathrm{O}_{\mathrm{n}}$

2 grol $\mathrm{KMnO}_{4} \sim 5$ grat $0 \sim 10 \times 1 / 2$ grat $\mathrm{O}$

1 grol $\mathrm{KMnO}_{4} \sim 5 \times 1 / 2$ grat $\mathrm{O}$

1 grol $\mathrm{KMnO}_{4}=5$ grek $\mathrm{KMnO}_{4}$

1 grol $\mathrm{KMnO}_{4}=1 / 5$ grol $\mathrm{KMnO}_{4}$

b. $2 \mathrm{KMnO}_{4}$ (basa) $\rightarrow \mathrm{K}_{2} \mathrm{O}+2 \mathrm{MnO}+3 \mathrm{O}_{\mathrm{n}}$

2 grol $\mathrm{KMnO}_{4} \sim 3$ grat $0 \sim 6 \times 1 / 2$ grat $\mathrm{O}$

1 grol $\mathrm{KMnO}_{4} \sim 3 \times 1 / 2$ grat $\mathrm{O}$

1 grol $\mathrm{KMnO}_{4}=3$ grek $\mathrm{KMnO}_{4}$

1 grol $\mathrm{KMnO}_{4}=1 / 3$ grol $\mathrm{KMnO}_{4}$

c. $\mathrm{K}_{2} \mathrm{Cr}_{2} \mathrm{O}_{7} \rightarrow \mathrm{K}_{2} \mathrm{O}+\mathrm{Cr}_{2} \mathrm{O}_{3}+3 \mathrm{O}_{\mathrm{n}}$

1 grol $\mathrm{K}_{2} \mathrm{Cr}_{2} \mathrm{O}_{7} \sim 3$ grat $\mathrm{O} \sim 6 \times 1 / 2$ grat $\mathrm{O}$

1 grol $\mathrm{K}_{2} \mathrm{Cr}_{2} \mathrm{O}_{7}=6$ grek $\mathrm{K}_{2} \mathrm{Cr}_{2} \mathrm{O}_{7}$

1 grek $\mathrm{K}_{2} \mathrm{Cr}_{2} \mathrm{O}_{7}=1 / 6$ grol $\mathrm{K}_{2} \mathrm{Cr}_{2} \mathrm{O}_{7}$

Contoh reduktor :

a. $2 \mathrm{~F}_{2} \mathrm{SO}_{4}+\mathrm{O}+\mathrm{H}_{2} \mathrm{SO}_{4} \rightarrow \mathrm{Fe}_{2}\left(\mathrm{SO}_{4}\right)_{3}+\mathrm{H}_{2} \mathrm{O}$

1 grol $\mathrm{F}_{2} \mathrm{SO}_{4} \sim 1$ grat $\mathrm{O} \sim 2 \times 1 / 2$ grat $\mathrm{O}$

1 grol $\mathrm{F}_{2} \mathrm{SO}_{4} \sim 1 \times 1 / 2$ grat $\mathrm{O}$

1 grol $\mathrm{F}_{2} \mathrm{SO}_{4}=1$ grek $\mathrm{FeSO}_{4}$

1 grek $\mathrm{F}_{2} \mathrm{SO}_{4}=1 / 6$ grol $\mathrm{FeSO}_{4}$ b. $\mathrm{As}_{2} \mathrm{O}_{3}+2 \mathrm{O} \rightarrow \mathrm{As}_{2} \mathrm{O}_{5}$

1 grol $\mathrm{As}_{2} \mathrm{O}_{3} \sim 2$ grat $\mathrm{O} \sim 4 \times 1 / 2$ grat $\mathrm{O}$

1 grol $\mathrm{As}_{2} \mathrm{O}_{3}=4$ grek $\mathrm{As}_{2} \mathrm{O}_{3}$

1 grek $\mathrm{As}_{2} \mathrm{O}_{3}=1 / 4$ grol $\mathrm{As}_{2} \mathrm{O}_{3}$

2. Dengan sistem elektron

Oksidasi : peristiwa kehilangan elektron/pele-

pasan elektron

Contoh $: \mathrm{Fe}^{2+} \longrightarrow \mathrm{Fe}^{3+}+\mathrm{e}^{-}$

Reduksi : peristiwa pengikatan elektron

Contoh: $\mathrm{Cl}_{2}+2 \mathrm{e}^{-} \longrightarrow 2 \mathrm{Cl}^{-}$

Grek suatu oksidator/reduktor : banyaknya 1 molekul oksidator/reduktor dibagi jumlah elektron yang diikat/dilepaskan oleh 1 molekul oksidator/ reduktor.

Contoh oksidator :

a. $\mathrm{MnO}_{4}^{-}+8 \mathrm{H}^{+}+5 \mathrm{e}^{-} \longrightarrow \mathrm{Mn}^{2+}+4 \mathrm{H}_{2} \mathrm{O}$

1 grion $\mathrm{MnO}_{4}^{-} \sim 5 \mathrm{e}^{-}$

1 grion $\mathrm{MnO}_{4}^{-}=5$ grek $\mathrm{MnO}_{4}$

1 grek $\mathrm{KMnO}_{4}=1 / 5$ grol $\mathrm{KMnO}_{4}$

b. $\mathrm{Cr}_{2} \mathrm{O}_{7}{ }^{=}+14 \mathrm{H}^{+}+6 \mathrm{e}^{-} \longrightarrow 2 \mathrm{Cr}^{3+}+7 \mathrm{H}_{2} \mathrm{O}$

1 grion $\mathrm{Cr}_{2} \mathrm{O}_{7}=6 \mathrm{e}^{-}$

1 grion $\mathrm{Cr}_{2} \mathrm{O}_{7}{ }^{=}=6$ grek $\mathrm{Cr}_{2} \mathrm{O}_{7}{ }^{=}$

1 grek $\mathrm{K}_{2} \mathrm{Cr}_{2} \mathrm{O}_{7}{ }^{=}=1 / 6$ grek $\mathrm{K}_{2} \mathrm{Cr}_{2} \mathrm{O}_{7}$

Contoh reduktor :

a. $\mathrm{Fe}^{2+} \rightarrow \mathrm{Fe}^{3+}+\mathrm{e}^{-}$

1 grion $\mathrm{Fe}^{2+} \sim 1 \mathrm{e}^{-}$

1 grion $\mathrm{Fe}^{2+}=1$ grek $\mathrm{Fe}^{2+}$

1 grekl $\mathrm{FeSO}_{4}=1$ grol $\mathrm{FeSO}_{4}$

b. $\mathrm{C}_{2} \mathrm{O}_{4}{ }^{=} \longrightarrow 2 \mathrm{CO}_{2}+2 \mathrm{e}^{-}$

1 grion $\mathrm{C}_{2} \mathrm{O}_{4}{ }^{=}=2$ grek $\mathrm{C}_{2} \mathrm{O}_{4}{ }^{=}$

1 grek $\mathrm{C}_{2} \mathrm{O}_{4}{ }^{-}=1 / 2$ grol $\mathrm{C}_{2} \mathrm{O}_{4}{ }^{=}$

3. Dengan perubahan bilangan oksidasi

Grek suatu oksidator dapat ditetapkan pula dengan perubahan bilangan oksidasi dari unsur yang akan mengalami oksidasi.

Penggunaan bilangan oksidasi :

a. Bilangan oksidasi unsur bebas/tidak terkombinasi $=0$

b. Bilangan oksidasi hidrogen (kecuali hidrida) $=+1$

c. Bilangan oksidasi oksigen (kecuali peroksida) $=-2$ 
d. Bilangan oksidasi dari logam dalam senyawa (kecuali dalam hidrida) selalu positif

e. Bilangan oksidasi radikal/ion perubahan elektronnya

f. Bilangan oksidasi dari senyawa $=0$

Contoh oksidator :

a. $\mathrm{K} \quad \mathrm{Mn} \mathrm{O}_{4} \rightarrow \mathrm{Mn} \mathrm{S} \mathrm{O}_{4}$

$\begin{array}{llllll}+1 & +7 & -8 & +2 & +6 & -8\end{array}$

Perubahan bilangan oksidasi :

$+7 \longrightarrow+2=5$ unit

1 grek $\mathrm{KMnO}_{4}($ asam $)=1 / 5 \mathrm{KMnO}_{4}$

b. $\mathrm{K}_{2} \mathrm{Cr}_{2} \mathrm{O}_{7} \rightarrow \mathrm{Cr}_{2}\left(\mathrm{SO}_{4}\right)_{3}$

$+2+12 \quad-14 \quad+6 \quad-6$

Perubahan bilangan oksidasi :

$+12 \longrightarrow+6=6$ unit

1 grek $\mathrm{K}_{2} \mathrm{Cr}_{2} \mathrm{O}_{7}=1 / 6$ grol $\mathrm{K}_{2} \mathrm{Cr}_{2} \mathrm{O}_{7}$

Contoh reduktor :

a. $2 \mathrm{Fe} \mathrm{SO}_{4} \longrightarrow \mathrm{Fe}_{2}\left(\mathrm{SO}_{4}\right)_{3}$

$\begin{array}{llll}+2 & -2 & +6 & -6\end{array}$

Perubahan bilangan oksidasi 1 atom Fe :

$+2 \longrightarrow+3=1$ unit

1 grek $\mathrm{FeSO}_{4}=1 / 2$ grol $\mathrm{H}_{2} \mathrm{C}_{2} \mathrm{O}_{4}$

b. $\mathrm{H}_{2} \mathrm{C}_{2} \mathrm{O}_{4} \rightarrow 2 \mathrm{C} \quad \mathrm{O}_{2}$

$+2+6-8+4 \quad-4$

Perubahan bilangan oksidasi 2 atom $\mathrm{C}$ :

$+16 \longrightarrow+8=2$ unit

1 grek $\mathrm{H}_{2} \mathrm{C}_{2} \mathrm{O}_{4}=1 / 2$ grol $\mathrm{H}_{2} \mathrm{C}_{2} \mathrm{O}_{4}$

c. $\mathrm{AS}_{2} \mathrm{O}_{3} \rightarrow \mathrm{As}_{2} \mathrm{O}_{5}$

$\begin{array}{llll}+6 & -6 & +10 & -10\end{array}$

Perubahan bilangan oksidasi 2 atom asam :

$+6 \longrightarrow+10=4$ unit

1 grek $\mathrm{AS}_{2} \mathrm{O}_{3}=1 / 4$ grol $\mathrm{AS}_{2} \mathrm{O}_{3}$

\section{PEMBAHASAN}

Sebagaimana kita ketahui, bahwa molaritas suatu larutan secara langsung dapat dibuat dari penimbangan kristal suatu zat atau dapat dibuat dari pengenceran larutan pekatnya. Namun normalitas suatu larutan disamping tergantung pada molaritas larutan, sangat tergantung pula pada reaksi yang akan terjadi pada zat itu (Hargis, 1988). Ambil contoh berapakah normalitas dari: (a) 0,1 M larutan $\mathrm{H}_{3} \mathrm{PO}_{4}$ ?

(b) normalitas 15,80 gram $\mathrm{KMnO}_{4}$ yang dilarutkan dalam air sampai volume larutan $1 \mathrm{~L}$. Normalitas kedua larutan itu tidak bisa ditentukan karena reaksi zat tersebut belum diketahui. Apabila normalitas zat tersebut dapat dihitung, tanpa mengetahui reaksi yang akan terjadi pada zat itu, berarti telah terjadi kesalahan konsep terhadap konsep normalitas itu sendiri. Di laboratorium dijumpai botol reagen bertuliskan $\mathrm{H}_{3} \mathrm{PO}_{4} 0,1 \mathrm{~N}$ dan $\mathrm{KMNO}_{4}$ 0,1 N. Pertanyaan yang muncul dengan melihat etiket itu mungkin :" $\mathrm{H}_{3} \mathrm{PO}_{4} 0,1 \mathrm{~N}$ itu tadinya dibuat dari berapa molar $\mathrm{H}_{3} \mathrm{PO}_{4}$ ?" dan $\mathrm{KMnO}_{4} \mathrm{O}, 1 \mathrm{~N}$ itu tadinya dibuat dengan menimbang berapa gram kristal $\mathrm{KMnO}_{4}$ ?". Kalau reaksi $\mathrm{H}_{3} \mathrm{PO}_{4}$ itu nantinya : $\mathrm{H}_{3} \mathrm{PO}_{4}+\mathrm{NaOH} \longrightarrow$ $\mathrm{NaH}_{2} \mathrm{PO}_{4}+\mathrm{H}_{2} \mathrm{O}$, tentunya $\mathrm{H}_{3} \mathrm{PO}_{4} 0,1 \mathrm{~N}$ itu berasal dari $0,1 \mathrm{M} \mathrm{H}_{3} \mathrm{PO}_{4}$. Tetapi apabila reaksi nantinya : $\mathrm{H}_{3} \mathrm{PO}_{4}+2 \mathrm{NaOH} \longrightarrow \mathrm{Na}_{2} \mathrm{HPO}_{4}+2 \mathrm{H}_{2} \mathrm{O}$, maka $\mathrm{H}_{3} \mathrm{PO}_{4} 0,1 \mathrm{M}$ itu akan sama dengan $0,2 \mathrm{~N}$ $\mathrm{H}_{3} \mathrm{PO}_{4}$. Implikasi dari semua itu adalah jika kita memakai $\mathrm{O}, 1 \mathrm{~N} \mathrm{H}_{3} \mathrm{PO}_{4}$ yang tersedia di lab itu untuk perhitungan semua reaksi, tentunya akan terjadi kekeliruan yang besar. Analog dengan $\mathrm{H}_{3} \mathrm{PO}_{4}$ itu, maka $\mathrm{KMnO}_{4}$ akan mengalami hal yang sama, dalam arti kita harus mengetahui $\mathrm{KMnO}_{4}$ itu nantinya akan digunakan dalam suasana apa? Dengan demikian, secara umum normalitas larutan tidak dapat dibuat apabila reaksi zat itu tidak diketahui dan yang langsung dapat dibuat adalah molaritas larutan.Inilah salah satu pertimbangan, mengapa penggunaan normalitas pada kimia larutan perlu ditinjau ulang.

\section{PENUTUP}

Pengunaan normalitas dalam hitungan kimia larutan dirasakan sangat menyulitkan dan membingungkan sehingga penggunaannya perlu ditinjau ulang. Hal ini dikarenakan beberapa hal seperti tersebut di bawah ini.

a. Penyelesaian hitungan kimia larutan dengan menggunakan konsep normalitas, hanya dapat diselesaikan jika ekivalen zat yang bereaksi selalu sama. 
b. Normalitas larutan hanya dapat ditentukan bila ek atau mek zat itu dalam volum larutan tertentu dapat ditentukan atau persamaan reaksi yang akan terjadi pada zat itu telah diketahui dengan pasti. Secara umum, normalitas larutan suatu zat tidak dapat ditentukan atau dibuat secara langsung. Yang dapat langsung dibuat adalah molaritas larutan.

c. Perhitungan kimia secara langsung menggunakan normalitas tidak dapat dilakukan. Perhitungan dapat dilakukan bila dimulai dari molaritas larutan dan molaritas ini diubah menjadi normalitas dengan bantuan persamaan reaksi.

d. Saat ini, hitungan kimia dengan menggunakan molaritas banyak dilakukan, karena disamping tahap berfikir dalam menyelesaikan persoalan hitungan kimia menjadi lebih singkat, molaritas secara langsung dapat dibuat, dan konsep molaritas ini telah dikenal betul oleh mahasiswa sejak mereka masih di tingkat SMU.

e. Banyak buku metode analisis kimia, prose- durnya masih mengunakan normalitas yang membingungkan itu. Pada buku atau petunjuk praktikum itu hanya diketengahkan rumus-rumus mencari kadar zat yang tentunya sangat membingungkan. Hal ini mungkin dikarenakan buku itu dibuat dengan menggunakan buku-buku lama sebagai rujukan. Buku metode analisis seperti itu perlu disusun kembali dengan menggunakan molaritas sebagai dasar perhitungannya sehingga tidak membingungkan siswa maupun mahasiswa.

\section{DAFTAR PUSTAKA}

Carla R. Krieger. 1997. Stoigiometri : A Cognitive Approach to Teaching Stoikiometri. J. Chem. Educ. Vol. 74 No. 3 March 1977. p : $306-309$.

Depdikbud. 1995. Lampiran II. Keputusan Menteri Pendidikan dan Kebudayaan No. 061/U/1995 tanggal 25 Februari 1995. Kurikulum Sekolah Menengah Umum Garis-garis Besar Program Pengajaran (GBPP). Mata Pelajaran Kimia Kelas I, II, III. Jakarta: Depdikbud.

Hargis, Larry. G. 1988. Anayitical Chemistry. Principles and Techniques, USA: Prentice-Hall International, Inc.

Slamet Sudarmadji, Bambang Haryono, Suhardi. 1984. Prosedur Analisa untuk Bahan Makanan dan Pertanian. Yogyakarta : Liberty. 